\title{
Integrated Damage Sensing in Fibre-Reinforced Composites with Extremely Low Carbon Nanotube Loadings
}

\author{
Han Zhang, ${ }^{1}$ Manabu Kuwata, ${ }^{1}$ Emiliano Bilotti, ${ }^{1,2}$ and Ton Peijs ${ }^{1,2}$ \\ ${ }^{1}$ School of Engineering and Materials Science, Queen Mary University of London, Mile End Road, London E1 4NS, UK \\ ${ }^{2}$ Nanoforce Technology Ltd., Queen Mary University of London, Joseph Priestley Building, Mile End Road, London E1 4NS, UK \\ Correspondence should be addressed to Ton Peijs; t.peijs@qmul.ac.uk
}

Received 17 December 2014; Accepted 13 May 2015

Academic Editor: Nay Ming Huang

Copyright (c) 2015 Han Zhang et al. This is an open access article distributed under the Creative Commons Attribution License, which permits unrestricted use, distribution, and reproduction in any medium, provided the original work is properly cited.

\begin{abstract}
A nanoengineered hybrid composite system has been developed, with integrated damage sensing capabilities at extremely low carbon nanotube (CNT) contents. The employed simple spray coating technique offers good spatial control and the possibility of localized CNT deposition, especially near the fibre/matrix interface, solving traditional problems associated with the incorporation of nanofillers in fibre-reinforced composite laminates such as increased resin viscosity and filtering effects. Moreover, the employed spraying technology has good potential for industrial scale-up. In situ damage sensing based on standard composite tests has been demonstrated for the first time on hybrid glass fibre/CNT composites using extremely low CNT loadings (below $0.1 \mathrm{wt} . \%$ ) and shows great potential for localized structural health monitoring by controlled CNT deposition into damage prone zones.
\end{abstract}

\section{Introduction}

Because of the increasing trend of using fibre-reinforced plastics to replace traditional structural materials like metals for various applications including aircraft and automotive, structural health monitoring in composites has become more important than ever. Due to their laminated nature, outstanding in-plane properties are accompanied with relatively weak out-of-plane performance in both glass fibre and carbon fibre-reinforced plastics. Traditional nondestructive testing methods involve the monitoring of internal failure modes typically associated with out-of-plane properties such as delamination or interlaminar shear failure and include techniques such as radiography or ultrasonic scan. Unfortunately, the examination of such part is often associated with a significant downtime and always leads to additional maintenance costs. Hence, the in situ and integrated health monitoring of structural composites is highly desirable for industry.

Owing to their excellent mechanical and electrical properties, carbon nanotubes (CNTs) have become one of the most used fillers to enhance composites' performance [15]. The use of CNTs for this purpose has additional benefits as these conductive nanofillers allow for the creation of multifunctional composites with integrated sensing capabilities [6-10], especially for structural health monitoring and damage sensing purposes [11-14]. Various outer stimuli can be sensed by percolated CNT networks within polymer matrices, such as strain [15-18], temperature [8], gas [19, 20], and polymer degradation [21]. Thostenson and Chou [9] have shown that using high shear mixing processes, CNTs can be dispersed in epoxy resins with the aim of sensing damage during a specifically designed tensile test. Traditionally, nanofillers like CNTs are introduced by mixing them into bulk resins such as epoxies before subsequent composite manufacturing, leading to an increase in viscosity of the resins, which interferes with manufacturing processes such as resin transfer moulding (RTM) or prepregging. Moreover, even after dispersion, the CNTs tend to agglomerate over time [22] nullifying their advantage as a nanofiller. In addition, the flow of these CNT modified resins through textile preforms such as woven fabrics can lead to filtering effects [23] by these textile preforms and uneven distribution of the nanofiller throughout the composite part. Hence, spatial control of CNTs in the epoxy matrix is not feasible using such conventional mixing strategies. 
A solution to this problem comes from coating fibre surfaces with CNTs using techniques such as electrophoresis deposition or in situ growth. Kepple et al. [24] showed improved interlaminar fracture toughness by about $50 \%$ with functionalized CNTs in situ grown onto carbon fibre fabrics. Another method is by introducing them into a fibre sizing. Gao et al. [25] introduced CNTs into composite laminates through a CNT modified sizing with the aim of in situ impact damage sensing. However, the complex processing steps involved and cost of these techniques limit productivity and its ability of scale-up.

Spraying techniques are among the simplest methods to deposit and disperse nanomaterials onto substrates, using strong airflows to generate very fine droplets, creating a spray which can be directly delivered onto films, fabrics, or fibres [26]. Very recently, studies based on spraying technique for mechanical reinforcement of fibre-reinforced plastics (FRPs) have been reported [26-28]. Joshi and Dikshit [28] deposited CNTs onto a film and then transferred this onto prepregs for toughening and Yavari et al. [29] sprayed graphene nanoplatelets onto glass fibres for improved fatigue properties, while Thakre et al. [30] have deposited single wall carbon nanotubes onto fibre preforms for interlaminar fracture toughness, although the improvements reported were limited. Zhang et al. utilized this method for CNTs deposition on carbon fibre prepregs and obtained improved mechanical properties [12]. However, to the best of authors' knowledge, no research works had been performed on utilizing this simple and effective method to deposit CNTs into glass fibrereinforced plastics (GRP) for damage sensing purposes.

In the present work, an airbrushing technique is used for the first time to integrate damage sensing capability into GRP. It is shown that such a spraying technique achieves good CNT distribution, localization, and spatial control. As such the work demonstrates that it is possible to overcome existing processing issues such as increased resin viscosity through the introduction of CNTs in resins, since nanofillers are introduced in the fibre preform rather than in the resin. At the same time spraying provides a cheap and easy scalable method that can be applied to any fibre surface with the possibility of localizing CNTs in damage prone regions.

\section{Materials and Methods}

2.1. Materials. The composites system in this study was based on a $2 \times 2$ twill glass fibre woven fabric (Sigmatex Ltd., UK) and an epoxy resin system RTM6-2 (HexFlow). Nonfunctionalized, high aspect ratio $(>150)$ multiwalled carbon nanotubes (MWCNTs) produced by chemical vapour deposition (CVD) were used as received from Nanocyl S.A. (Product number NC7000), where detailed characterization can be found in [31,32]. Methanol (Sigma-Aldrich) was used as solvent for CNTs suspension.

2.2. Spray Coating Technique. The various steps of the process are schematically depicted in Figure 1. Measured amounts of CNTs were dispersed into methanol, using an ultrasonication probe to break down the CNTs agglomerates, with 20\% of maximum amplitude and 5000 joules of energy. After sonication, the CNT solution was placed into an airbrush container for spraying deposition. The airbrushing setup (Iwata Performance plus model H4001 HP-CPLUS) was connected with an air compressor (Iwata studio series), providing $30 \mathrm{psi}$ ( 2.0 bars) of air pressure with $10 \mathrm{~cm}$ distance between spraying nozzle and substrate. The spray coating process was repeated with constant pattern to cover complete preform until the prepared CNT suspension has finished.

For interlaminar fracture toughness test specimen, six plies of glass fibre fabric all in $0 / 90^{\circ}$ configuration were employed, with five plies single-sided sprayed with $4 \mathrm{mg}$ CNTs on each layer. For interlaminar shear strength (ILSS) test specimen, same spraying procedures were used but here $10 \mathrm{mg}$ instead of $4 \mathrm{mg}$ of CNTs was deposited onto each layer. The spraying process was repeated in a controlled manner until all of the CNT solution was deposited onto the fabric substrate.

2.3. Specimen Manufacturing and Preparation. Two parts of epoxy resins were preheated to $80^{\circ} \mathrm{C}$ before they were mixed with the weight ratio of 59.5 to 40.5 between epoxy and hardener. After degassing the epoxy resin for $30 \mathrm{~min}$ in a vacuum oven, the infusion process was carried out under a vacuum of 1 bar at $90^{\circ} \mathrm{C}$. Vacuum assisted resin infusion (VARI) was used for the manufacturing of the composite laminates, followed by a typical curing cycle that involved $140^{\circ} \mathrm{C}$ for $1.5 \mathrm{hrs}$ and a postcure at $180^{\circ} \mathrm{C}$ for another $2 \mathrm{hrs}$. After curing, the composite laminates were cut into $135 \mathrm{~mm} \times$ $20 \mathrm{~mm}$ double cantilever beam (DCB) specimens for Mode-I interlaminar testing. The exposed edges at the specimen ends were connected with copper wire and silver paint. Regarding sensing of short beam strength (SBS) specimens for ILSS testing, both in-plane and through-thickness direction were used in the sensing test, as shown in Figure 2. Thin copper wire was positioned at both ends of the specimen for inplane measurements, while, for through-thickness, silver conductive paint was applied to the surface and bottom of specimen, before copper wire was attached by a silver-loaded epoxy adhesive.

2.4. Characterization. For electrical measurements, a digital multimeter (Agilent 34401A) was used to measure the volumetric resistance of each specimen using a two-probe direct current measurement setup. Electrodes were directly connected with copper wires from specimen edges, as shown in Figure 2. For interlaminar fracture toughness testing, double cantilever beam tests were performed according to ASTM D5528 [33], using an Instron 5566 universal testing machine at a test speed of $1 \mathrm{~mm} / \mathrm{min}$, while, for interlaminar shear strength (ILSS) evaluation, SBS tests were performed in accordance with ASTM D2344 at the same testing machine and a crosshead speed of $1 \mathrm{~mm} / \mathrm{min}$.

The scanning electron microscope (SEM) used in this work is an Inspect F model from FEI. Morphologies of deposited CNTs on glass fibre surfaces as well as fracture surfaces of specimens after tests were examined under SEM. The fracture surface was gold-coated before examination. 


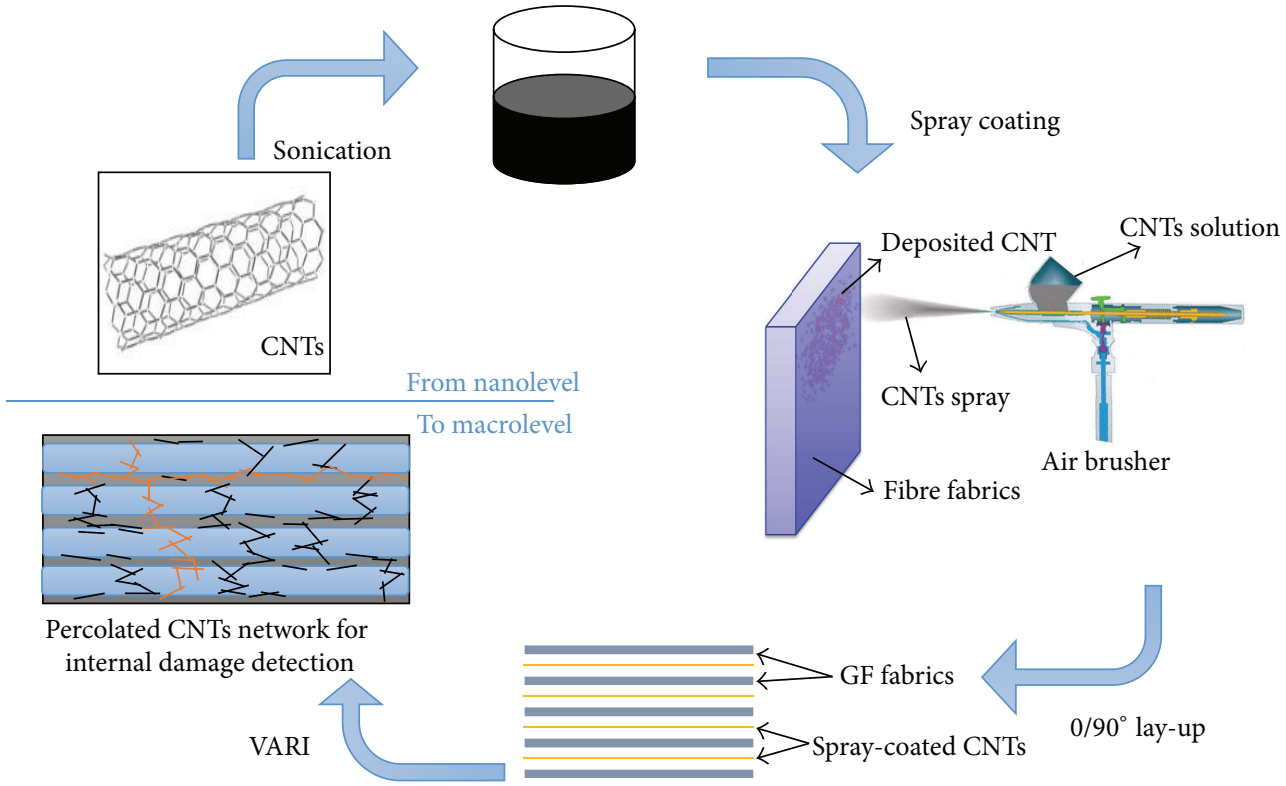

FIGURE 1: Schematic illustration of CNT spray coating and laminate fabrication process. Glass fibre fabrics are spray-coated on one side and subsequently stacked together for resin infusion using a vacuum assisted resin infusion process.

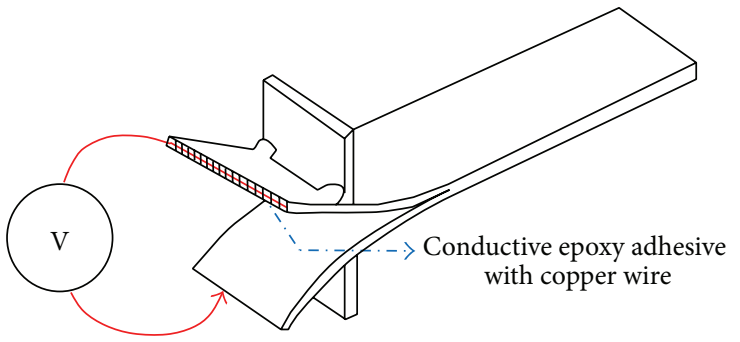

(a)
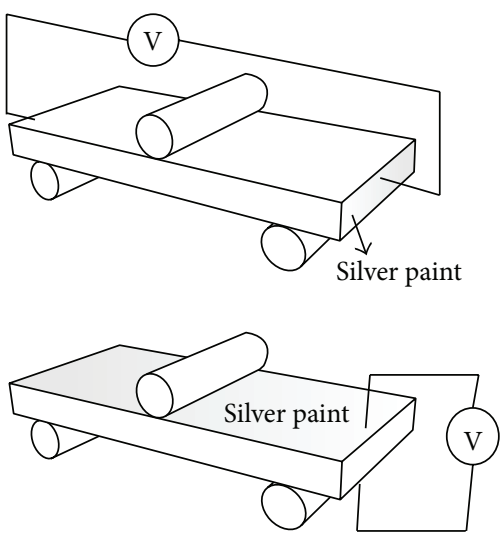

(b)

FIGURE 2: Illustration of in situ damage sensing setup for (a) DCB tests and (b) SBS tests.

\section{Results and Discussion}

A fine percolated network of CNTs onto the glass fibres is observed after spray coating (Figures $3(a)$ and $3(b)$ ). No obvious large CNT aggregates are apparent and localization of CNTs in the damage prone interfacial zone has been achieved. The CNTs deposited by airbrushing are positioned not only at the fibre surface but also near the interfacial or matrix regions in between individual fibres. This is attributed to two main factors: first, the strong airflow during airbrush deposition which directly positions CNTs within the spacing between individual glass fibres and secondly, the infusion process during VARI which allows for some of CNT migration into the glass fibre bundles, especially as a result of throughthickness resin flow.
From the SEM fracture surface images of the ModeI tested composite laminates (Figure 3(c)), it can be seen that glass fibres are covered by epoxy, indicating good adhesion between fibres and resin with the presence of CNTs. CNTs could also be found on both fibre surfaces and connected interfacial regions between fibres and matrix, which can contribute to enhanced stress transfer compared to composites based on neat resins. The well-dispersed electrically conductive CNT network within these glass fibre laminates can now be used for damage sensing through the monitoring of resistivity changes with progressive cracking. Figures 3(d) and 3(e) show the cross-sectional areas of GRP reference specimen and hybrid CNT/GRP specimen after SBS tests, respectively, where very clear interlaminar shear failures were observed. 


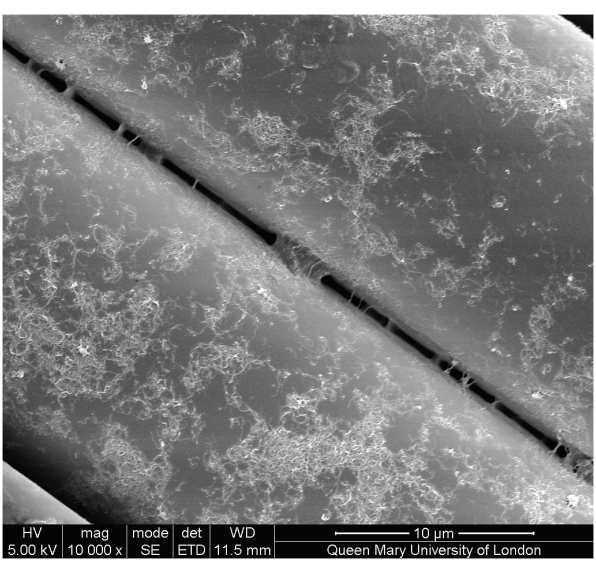

(a)

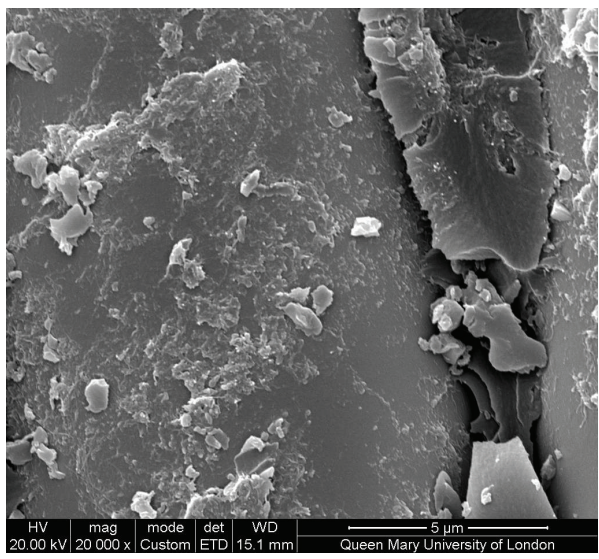

(c)

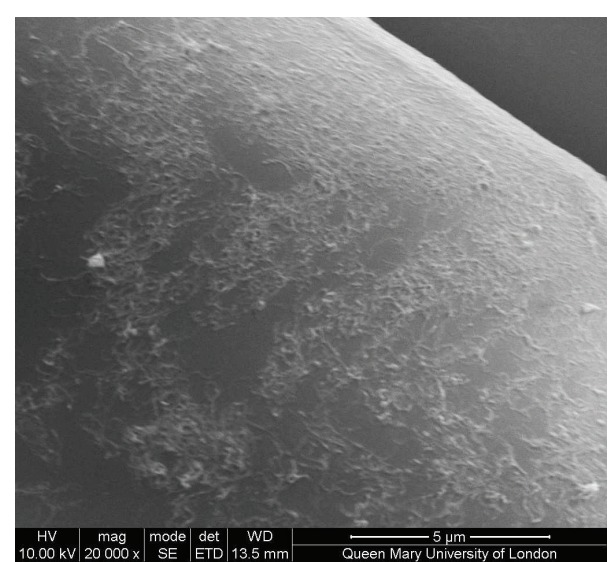

(b)

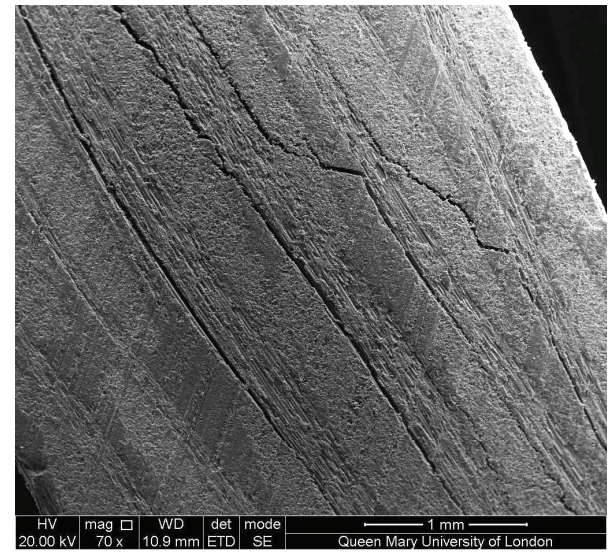

(d)

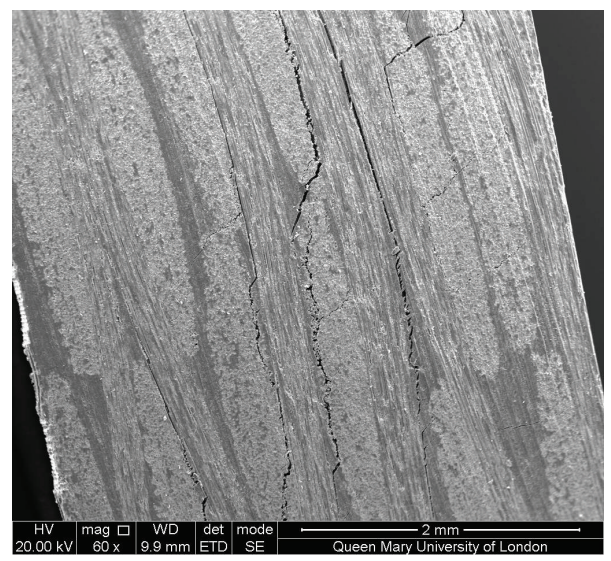

(e)

FIGURE 3: SEM images of (a) percolated CNT network on glass fibre surface and in interfacial regions; (b) higher magnification showing deposited networks on fibre surface; (c) fracture surface of DCB tested specimen with CNTs presented; (d) cross-sectional area of reference specimen after SBS test; and (e) cross-sectional area of CNT/GRP hybrid specimen after SBS test.

Using spray coating technology, a concentration of as little as $0.012 \mathrm{wt} . \% \mathrm{CNTs}$ is able to introduce electrical conductivity into the composite laminates, indicating excellent network formation. This extremely low CNT loading is chosen due to our previous sensing experience based on percolated networks that sensitivity of the composites upon outer stimuli will be reduced if CNT loading is well above percolation threshold $[15,34]$. The obtained electrical conductivity is believed to be not solely attributed to the initial dispersion of CNTs onto the fibre surfaces, but also the result of a "dynamic percolation" process $[15,34]$ to take place after the infusion process but before complete cross-linking of the epoxy resin. 


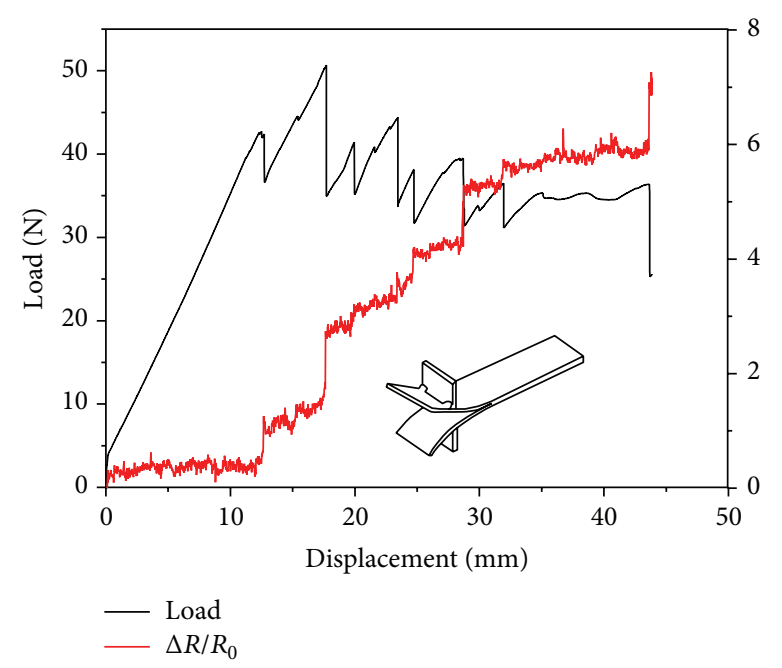

(a)

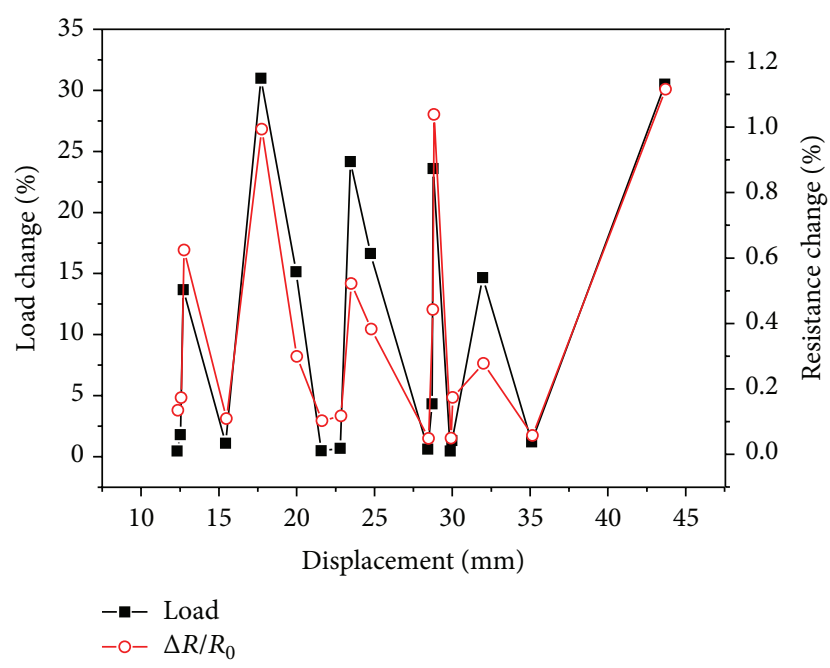

(b)

FIGURE 4: (a) In situ damage sensing results showing measured volumetric electrical resistivity during DCB testing, accompanied with loaddisplacement curves; (b) correlation between relative resistivity and load change (in percentage).

Figure 4(a) shows the damage sensing results together with a typical load-displacement curve from the DCB test. The successive drops in the load curve are due to crack propagation. The simultaneously measured resistivity increases with clear steps which directly correlate with the load drops and is due to the percolated CNT network being affected by crack propagation. This correlation confirms that the spraycoated conductive CNT network on the glass fibre fabrics can be used as a sensing tool to detect damage within the composite specimens during mechanical deformation.

To further confirm the correlation between mechanical performance and electrical sensing signals, the relative force and resistivity change (in percentage) is plotted (Figure 4(b)). The relative change of load and resistance was taken from the data separately and plotted as a function of displacement. Excellent correlation between these two signals is observed, indicating the reliability of this technique to detect delamination damage in composite laminates. Although the measured interlaminar fracture toughness $\left(G_{\text {IC }}\right)$ of the CNT modified laminates $\left(0.52 \pm 0.09 \mathrm{~kJ} / \mathrm{m}^{2}\right)$ was only slightly higher than that of the reference laminate $\left(0.44 \pm 0.05 \mathrm{~kJ} / \mathrm{m}^{2}\right)$, the spray coating approach did show some promise in improving interlaminar toughness, taking into account the extremely low CNT concentration (0.012 wt.\%) used. Again this stresses the advantage of CNT localization at damage prone zones or interfacial regions to improve its efficiency.

The in situ damage sensing work was also applied to SBS tests to examine its effectiveness under flexure loadings. Both in-plane and through-thickness direction were used to apply an electrical field for sensing; unfortunately, no electrical signals were recorded in through-thickness specimens. This is believed to be due to two main reasons: (i) the relatively low CNT loading in the composites (0.072 wt.\%) and (ii) the appearance of resin rich regions near the surface of the specimens leading to higher electrical resistance. Hence, only in-plane sensing results were successfully obtained and employed to analyse the internal damage during the SBS test.

Figure 5 shows the load curves together with the normalized electrical sensing signals. For the SBS test, the force starts to build up from beginning of the test, until interlaminar shear failure occurs which leads to an obvious drop of the force before the end of the test. Clearly, at the beginning of the test, the sensing signal was not much affected by the applied load but is maintained at its initial starting level. It is worth noting that the electrical resistance was actually slightly reduced with increased loading, which was due to the flexural deformation which involves partly compression of the specimen and a slightly reduced gap between CNTs within the network. This finding is consistent with other researches $[16,35]$. When interlaminar shear failure occurs, the network structure of the percolated CNTs is severely affected, leading to a dramatic change in sensing signals. From the enlarged graph near the ultimate failure load (Figure 5(b)), it can be seen very clearly that also here the measured electrical sensing signals correlate well with the applied load, with the highest resistance change occurring near the final failure of the specimen.

Table 1 summarizes the observed mechanical properties of the nanoengineered hybrid composites. As expected, with the extremely low CNT loadings employed in this study, no major improvements in both interlaminar fracture toughness and interlaminar shear strength were observed. However, more importantly, mechanical property levels were sustained at their initial levels while at the same time multifunctionality was introduced through a damage sensing capability.

\section{Conclusions}

A hybrid micronanocomposite with integrated damage sensing capabilities was prepared using extremely low CNT concentrations. In situ damage sensing was established based on 
TABLE 1: Summary table for mechanical properties of glass/epoxy laminates with and without CNT spray coating.

\begin{tabular}{lcccc}
\hline & Reference & With CNT spray coating & Relative change (\%) & CNT loading (wt.\%) \\
\hline$G_{\text {IC }}\left(\mathrm{kJ} / \mathrm{m}^{2}\right)$ & $0.44( \pm 0.05)$ & $0.52( \pm 0.09)$ & $+18 \%$ & 0.012 \\
ILSS $(\mathrm{MPa})$ & $38.35( \pm 2.12)$ & $40.25( \pm 0.82)$ & $+5 \%$ & 0.072 \\
\hline
\end{tabular}

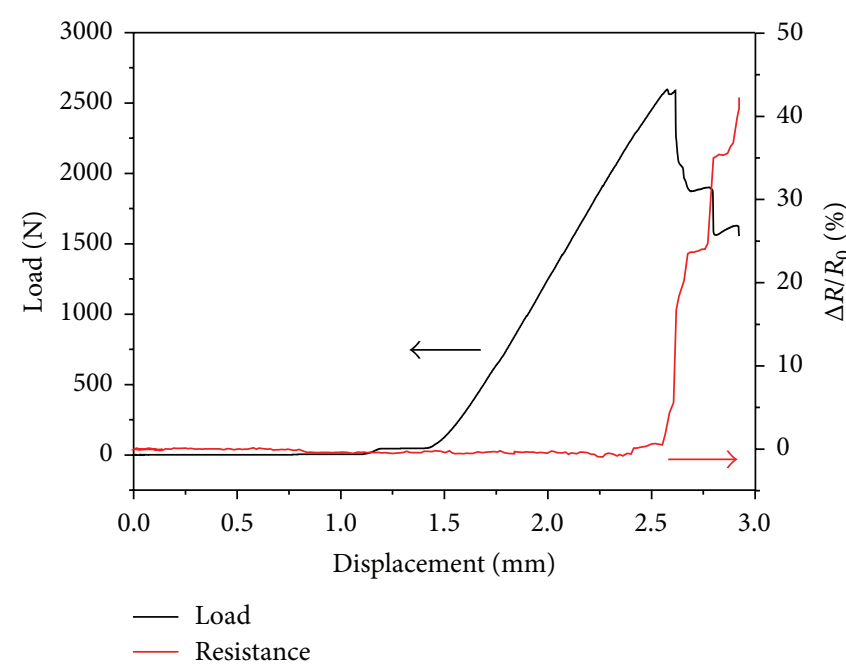

(a)

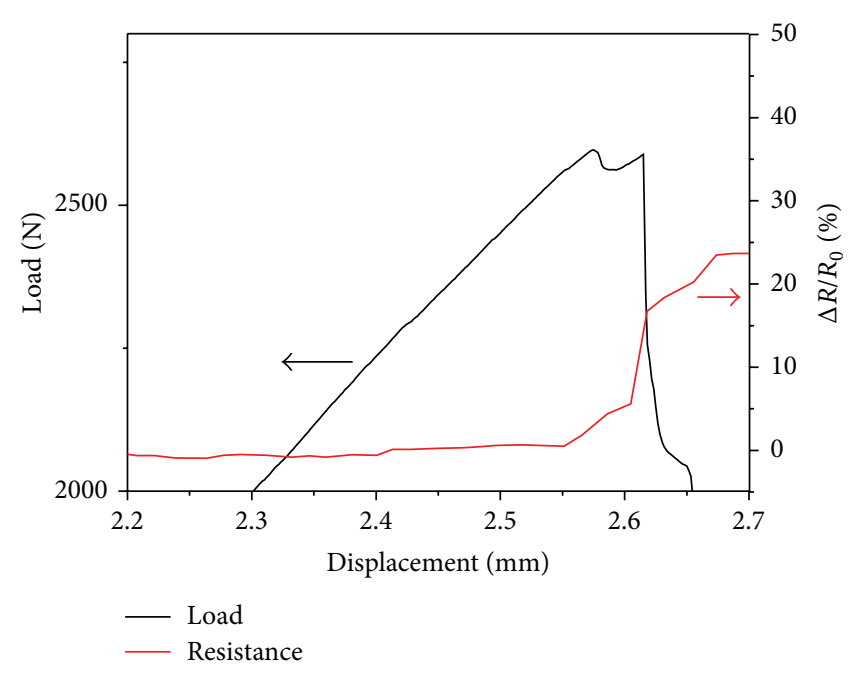

(b)

FIGURE 5: Damage sensing results for ILSS test: (a) load curve with in-plane sensing results; (b) zoomed in area near the failure load.

standard composite tests. An airbrushing technique proved to be a highly effective method to disperse and deposit CNTs onto fibre textile preforms with great spatial control and potential for localization, introducing damage sensing capabilities into glass fibre composite laminates. Apart from its simplicity and versatility, spraying also allows for a relatively easy industrial scale-up. The highly effective percolated CNT networks obtained were utilized to detect interlaminar damage in real time, while simultaneously providing some mechanical property improvement.

\section{Conflict of Interests}

The authors declare that there is no conflict of interests regarding the publication of this paper.

\section{Acknowledgment}

This research work was carried out under the framework of the European Research Programme "IMS \& CPS" in the Seventh Framework Programme.

\section{References}

[1] J. N. Coleman, U. Khan, W. J. Blau, and Y. K. Gun'ko, "Small but strong: a review of the mechanical properties of carbon nanotube-polymer composites," Carbon, vol. 44, no. 9, pp. 16241652, 2006.

[2] Y. N. Xia, P. D. Yang, Y. G. Sun et al., "One-dimensional nanostructures: synthesis, characterization, and applications," Advanced Materials, vol. 15, no. 5, pp. 353-389, 2003.
[3] E. T. Thostenson, Z. F. Ren, and T.-W. Chou, "Advances in the science and technology of carbon nanotubes and their composites: a review," Composites Science and Technology, vol. 61, no. 13, pp. 1899-1912, 2001.

[4] F. Inam, D. W. Y. Wong, M. Kuwata, and T. Peijs, "Multiscale hybrid micro-nanocomposites based on carbon nanotubes and carbon fibers," Journal of Nanomaterials, vol. 2010, Article ID 453420, 12 pages, 2010.

[5] J. Doshi and D. H. Reneker, "Electrospinning process and applications of electrospun fibers," Journal of Electrostatics, vol. 35, no. 2-3, pp. 151-160, 1995.

[6] C. Li, E. T. Thostenson, and T.-W. Chou, "Sensors and actuators based on carbon nanotubes and their composites: a review," Composites Science and Technology, vol. 68, no. 6, pp. 1227-1249, 2008.

[7] V. P. Veedu, A. Cao, X. Li et al., "Multifunctional composites using reinforced laminae with carbon-nanotube forests," Nature Materials, vol. 5, no. 6, pp. 457-462, 2006.

[8] J. R. Wood, Q. Zhao, M. D. Frogley et al., "Carbon nanotubes: from molecular to macroscopic sensors," Physical Review B: Condensed Matter and Materials Physics, vol. 62, no. 11, pp. 75717575, 2000.

[9] E. T. Thostenson and T.-W. Chou, "Carbon nanotube networks: sensing of distributed strain and damage for life prediction and self healing," Advanced Materials, vol. 18, no. 21, pp. 2837-2841, 2006.

[10] J.-M. Park, D.-S. Kim, J.-R. Lee, and T.-W. Kim, "Nondestructive damage sensitivity and reinforcing effect of carbon nanotube/epoxy composites using electro-micromechanical technique," Materials Science \& Engineering C: Biomimetic and Supramolecular Systems, vol. 23, no. 6-8, pp. 971-975, 2003. 
[11] N. de Greef, L. Gorbatikh, A. Godara, L. Mezzo, S. V. Lomov, and I. Verpoest, "The effect of carbon nanotubes on the damage development in carbon fiber/epoxy composites," Carbon, vol. 49, no. 14, pp. 4650-4664, 2011.

[12] H. Zhang, Y. Liu, M. Kuwata, E. Bilotti, and T. Peijs, "Improved fracture toughness and integrated damage sensing capability by spray coated CNTs on carbon fibre prepreg," Composites Part A: Applied Science and Manufacturing, vol. 70, pp. 102-110, 2015.

[13] J.-M. Park, D.-S. Kim, S.-J. Kim, P.-G. Kim, D.-J. Yoon, and K. L. DeVries, "Inherent sensing and interfacial evaluation of carbon nanofiber and nanotube/epoxy composites using electrical resistance measurement and micromechanical technique," Composites Part B: Engineering, vol. 38, no. 7-8, pp. 847861, 2007.

[14] T.-W. Chou, L. Gao, E. T. Thostenson, Z. Zhang, and J.-H. Byun, "An assessment of the science and technology of carbon nanotube-based fibers and composites," Composites Science and Technology, vol. 70, no. 1, pp. 1-19, 2010.

[15] E. Bilotti, H. Zhang, H. Deng, R. Zhang, Q. Fu, and T. Peijs, "Controlling the dynamic percolation of carbon nanotube based conductive polymer composites by addition of secondary nanofillers: the effect on electrical conductivity and tuneable sensing behaviour," Composites Science and Technology, vol. 74, pp. 85-90, 2013.

[16] L. Böger, M. H. G. Wichmann, L. O. Meyer, and K. Schulte, "Load and health monitoring in glass fibre reinforced composites with an electrically conductive nanocomposite epoxy matrix," Composites Science and Technology, vol. 68, no. 7-8, pp. 1886-1894, 2008.

[17] I. P. Kang, M. J. Schulz, J. H. Kim, V. Shanov, and D. L. Shi, "A carbon nanotube strain sensor for structural health monitoring," Smart Materials \& Structures, vol. 15, no. 3, pp. 737-748, 2006.

[18] J. Sebastian, N. Schehl, M. Bouchard et al., "Health monitoring of structural composites with embedded carbon nanotube coated glass fiber sensors," Carbon, vol. 66, pp. 191-200, 2014.

[19] D. H. Reneker and I. Chun, "Nanometre diameter fibres of polymer, produced by electrospinning," Nanotechnology, vol. 7, no. 3, pp. 216-223, 1996.

[20] R. Olejnik, P. Slobodian, P. Riha, and P. Saha, "An electrically conductive and organic solvent vapors detecting composite composed of an entangled network of carbon nanotubes embedded in polystyrene," Journal of Nanomaterials, vol. 2012, Article ID 365062, 7 pages, 2012.

[21] F. Mai, Y. Habibi, J.-M. Raquez et al., "Poly(lactic acid)/carbon nanotube nanocomposites with integrated degradation sensing," Polymer, vol. 54, no. 25, pp. 6818-6823, 2013.

[22] F. Inam and T. Peijs, "Re-agglomeration of carbon nanotubes in two-component epoxy system," Journal of Nanostructured Polymers and Nanocomposites, vol. 2, no. 3, p. 9, 2006.

[23] E. F. R. da Costa, A. A. Skordos, I. K. Partridge, and A. Rezai, "RTM processing and electrical performance of carbon nanotube modified epoxy/fibre composites," Composites Part A: Applied Science and Manufacturing, vol. 43, no. 4, pp. 593-602, 2012.

[24] K. L. Kepple, G. P. Sanborn, P. A. Lacasse, K. M. Gruenberg, and W. J. Ready, "Improved fracture toughness of carbon fiber composite functionalized with multi walled carbon nanotubes," Carbon, vol. 46, no. 15, pp. 2026-2033, 2008.

[25] L. Gao, T. W. Chou, E. T. Thostenson, Z. Zhang, and M. Coulaud, "In situ sensing of impact damage in epoxy/glass fiber composites using percolating carbon nanotube networks," Carbon, vol. 49, no. 10, pp. 3382-3385, 2011.

[26] C. Robert, J. F. Feller, and M. Castro, "Sensing skin for strain monitoring made of PC-CNT conductive polymer nanocomposite sprayed layer by layer," ACS Applied Materials and Interfaces, vol. 4, no. 7, pp. 3508-3516, 2012.

[27] F. L. Shan, Y. Z. Gu, M. Li, Y. N. Liu, and Z. G. Zhang, "Effect of deposited carbon nanotubes on interlaminar properties of carbon fiber-reinforced epoxy composites using a developed spraying processing," Polymer Composites, vol. 34, no. 1, pp. 4150, 2013.

[28] S. C. Joshi and V. Dikshit, "Enhancing interlaminar fracture characteristics of woven CFRP prepreg composites through CNT dispersion," Journal of Composite Materials, vol. 46, no. 6, pp. 665-675, 2012.

[29] F. Yavari, M. A. Rafiee, J. Rafiee, Z.-Z. Yu, and N. Koratkar, "Dramatic increase in fatigue life in hierarchical graphene composites," ACS Applied Materials \& Interfaces, vol. 2, no. 10, pp. 2738-2743, 2010.

[30] P. R. Thakre, D. C. Lagoudas, J. C. Riddick et al., "Investigation of the effect of single wall carbon nanotubes on interlaminar fracture toughness of woven carbon fiber-epoxy composites," Journal of Composite Materials, vol. 45, no. 10, pp. 1091-1107, 2011.

[31] NANOCYL, NANOCYL NC7000 Series-Product DatasheetThin Multi-Wall Carbon Nanotubes, NANOCYL, Sambreville, Belgium, 2009.

[32] M. Keller, G. Kreck, Y. Holzapfel, N. Neubauer, and M. Seipenbusch, "Monitoring method for carbon nanotubes (CNT): personal sampler and corresponding reading device," in Proceedings of the 8th International Conference on Multi-Material Micro Manufacture, Stuttgart, Germany, November 2011.

[33] ASTM International, A. D. 5528-01, Standard Test Method for Mode I Interlaminar Fracture Toughness of Unidirectional FiberReinforced Polymer Matrix Composites, ASTM International, West Conshohocken, Pa, USA, 2001.

[34] R. Zhang, A. Dowden, H. Deng, M. Baxendale, and T. Peijs, "Conductive network formation in the melt of carbon nanotube/thermoplastic polyurethane composite," Composites Science and Technology, vol. 69, no. 10, pp. 1499-1504, 2009.

[35] T. Takeda, Y. Shindo, T. Fukuzaki, and F. Narita, "Short beam interlaminar shear behavior and electrical resistancebased damage self-sensing of woven carbon/epoxy composite laminates in a cryogenic environment," Journal of Composite Materials, vol. 48, no. 1, pp. 119-128, 2014. 

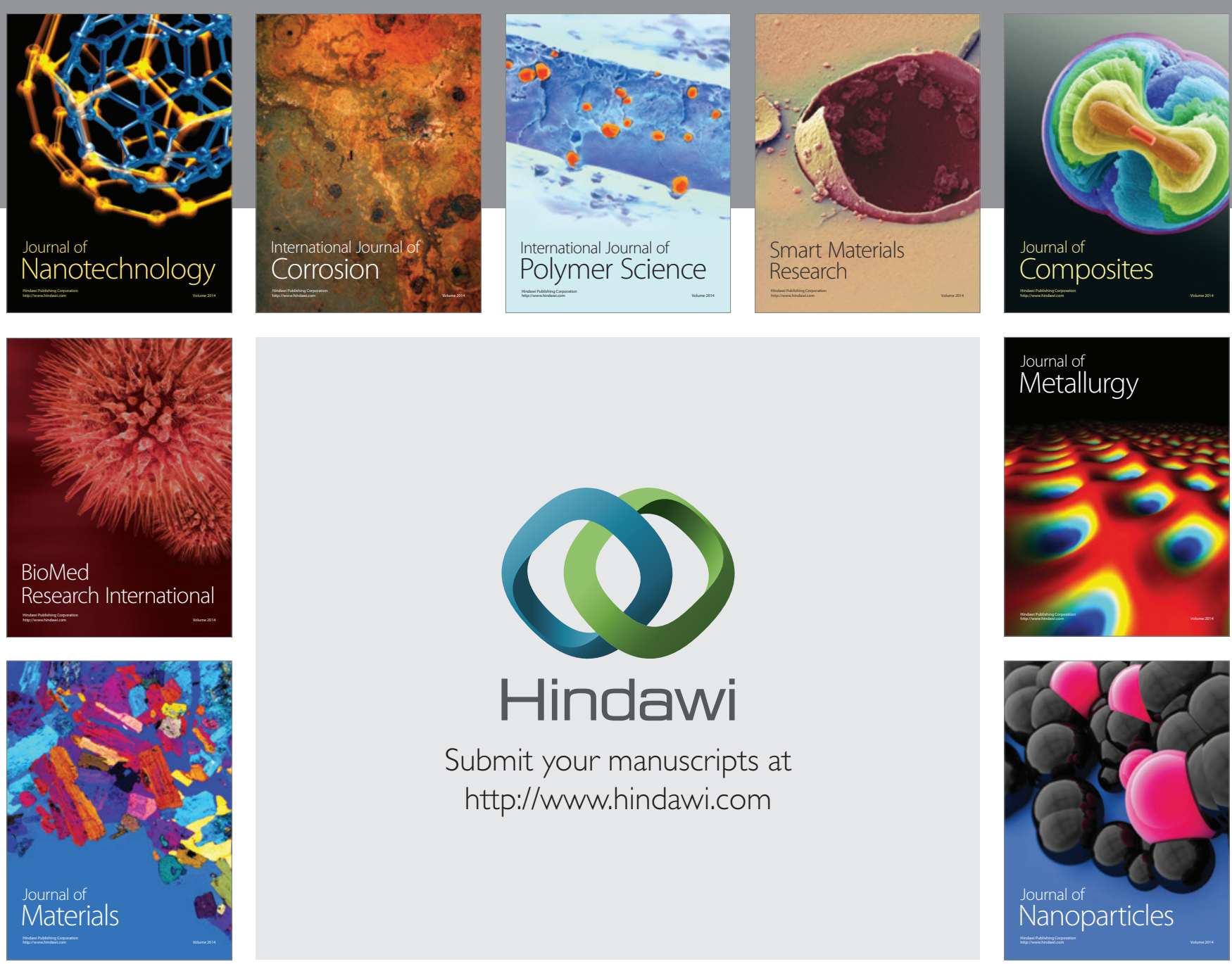

Submit your manuscripts at http://www.hindawi.com
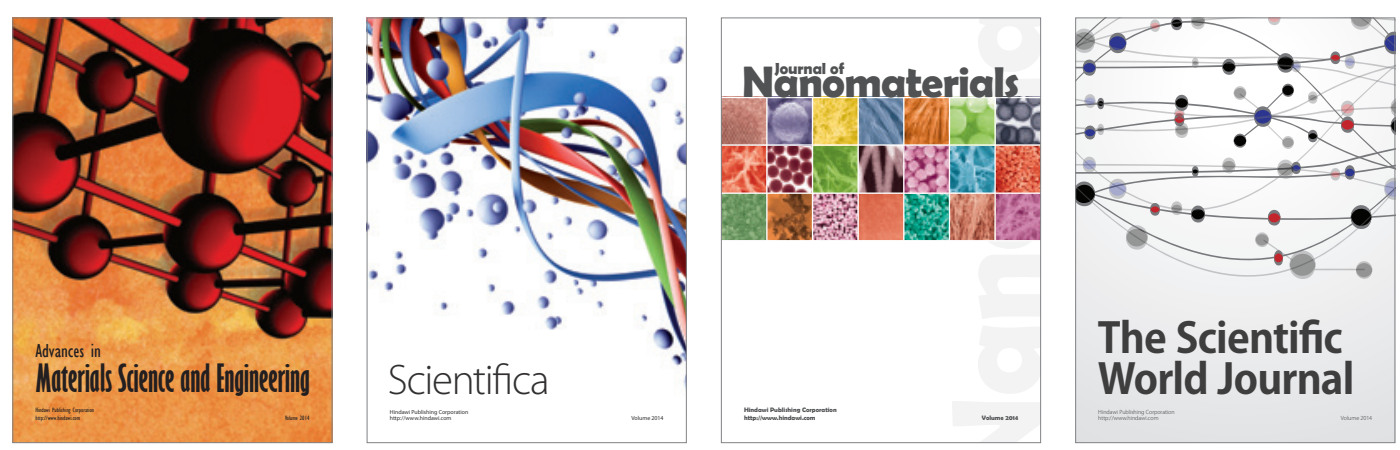

\section{The Scientific World Journal}
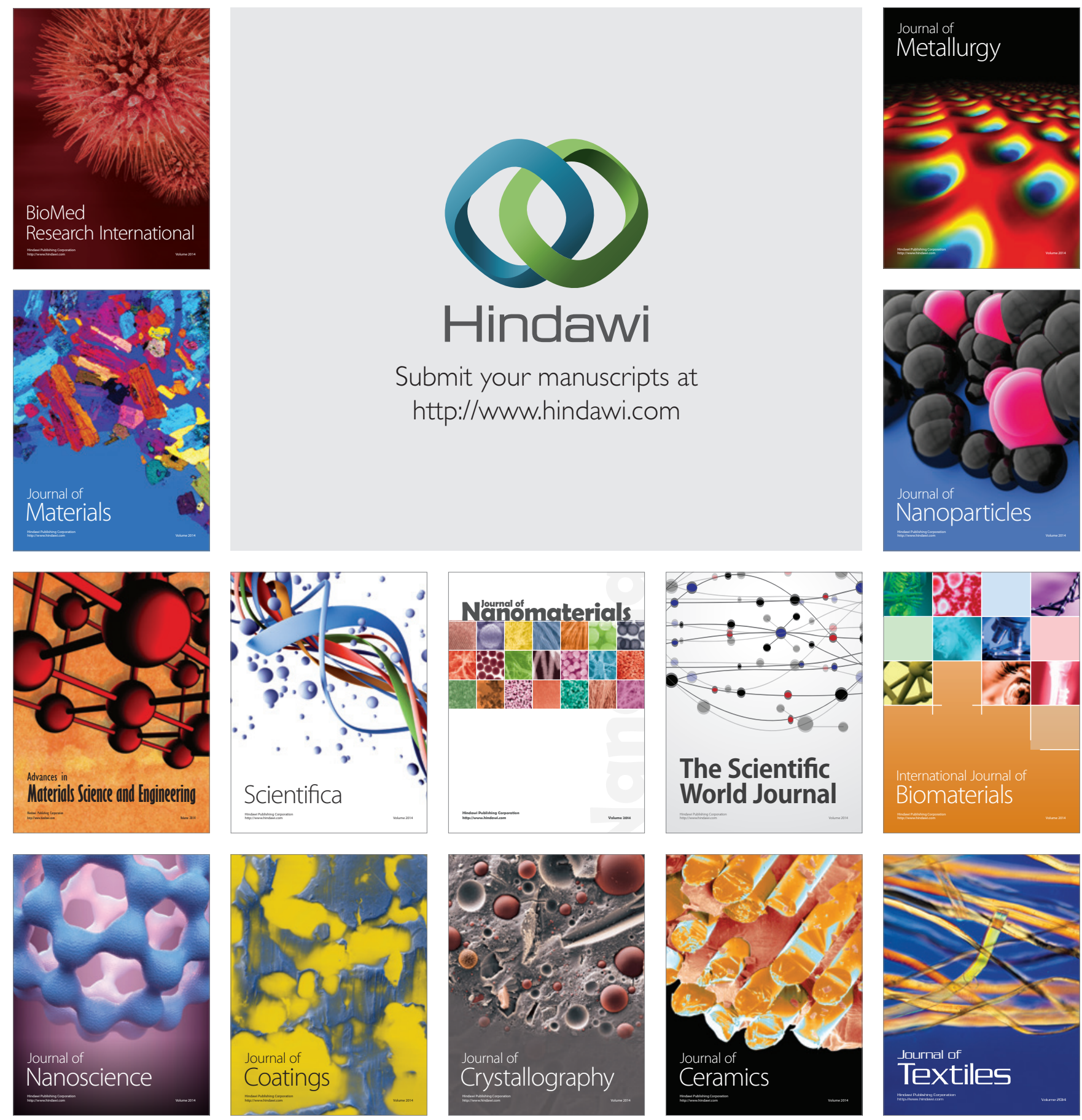